\title{
Chronic Suppurative Otitis Media
}

National Cancer Institute

\section{Source}

National Cancer Institute. Chronic Suppurative Otitis Media. NCI Thesaurus. Code C128386.

Otitis media that persists for at least six weeks, and that is associated with otorrhea through a perforated tympanic membrane. 